\title{
Socioeconomic status and health literacy as the important predictors of general health in Iran: A structural equation modeling approach
}

\section{Taiebeh Nadi}

Hamadan University of Medical Sciences School of Public Health

Jalal Poorolajal

Hamadan University of Medical Sciences School of Public Health

Amin Doosti-Irani ( $\square$ a_doostiirani@yahoo.com )

Hamadan University of Medical Sciences School of Public Health https://orcid.org/0000-0003-06237503

\section{Research}

Keywords: Health Literacy, health, Socioeconomic Factors, Iran

Posted Date: May 22nd, 2020

DOI: https://doi.org/10.21203/rs.2.22404/v2

License: (c) (1) This work is licensed under a Creative Commons Attribution 4.0 International License.

Read Full License 
The authors have withdrawn this preprint from Research Square 